\title{
Studies of the Cyclopolymerization in the Presence of Alkylaluminum Chlorides. II. Polymerizations of 2-(o-Allylphenoxy)ethyl Acrylate and 4-(o-Allylphenoxy)butyl Acrylate
}

\author{
Kazuaki Yokota, Toyoji KaKuchI, and Yoshiyuki TAKada \\ Department of Chemical Process Engineering, Faculty of \\ Engineering, Hokkaido University, Sapporo, Japan.
}

(Received March 5, 1976)

\begin{abstract}
The addition of alkylaluminum chlorides to 2-(o-allylphenoxy)ethyl acrylate (2-AOEA) and 4-(o-allylphenoxy)butyl acrylate (4-AOBA) has been reported to cause an increase in the cyclopolymerization tendency and to give polymers containing eleven- and thirteen-membered rings, respectively. At an $\mathrm{Al} / \mathrm{M}$ molar ratio of 1.0 or above, the extent of cyclization increased to $90-96 \%$ for 2 -AOEA and $89-93 \%$ for 4-AOBA. The cyclopolymerization tendency slightly decreased upon increasing the number of atoms between the acrylic and the allylic double bond, in the order of $o$-allylphenyl acrylate (APA) $>2$-AOEA $>4$-AOBA. The values of $k_{\mathrm{p}} / k_{\mathrm{c}}$, the ratio of rate constants for linear propagation and cyclization, for 2-AOEA and 4-AOBA were comparable to the value for acrylic anhydride, a symmetrical 1,6-diene, in the radical polymerization. The results suggested that the increase in the cyclopolymerization tendency would be caused by an intramolecular interaction between the two double bonds in the polymerization process. KEY WORDS 2-(o-Allylphenoxy)ethyl Acrylate / 4-(o-Allylphenoxy)butyl Acrylate / Cyclopolymerization / Radical Polymerization / Diethylaluminum Chloride / Ethylaluminum Sesquichloride / Ethylaluminum Dichloride / Cyclization Constant / Eleven-Membered Ring / Thirteen-Membered Ring /
\end{abstract}

In the cyclopolymerizations of nonconjugated diolefins the relative ease of ring formation is strongly dependent upon the number of ring atoms. ${ }^{1}$ In general, the cyclopolymerization tendency falls sharply for rings of more than six atoms and the variations are relatively small for rings of eight to twenty atoms. ${ }^{2,3}$ It has been suggested that an intramolecular interaction between two double bonds in the polymerization process may be important as one of the driving forces for cyclization in cyclopolymerization. ${ }^{4-6}$ Thus, if it is possible to find the reaction conditions causing such an interaction for the diolefins capable of forming medium and large rings, an increase of cyclopolymerization tendency can be expected.

Panzik and Mulvaney ${ }^{7}$ have carried out the cyclopolymerizations of $\mathrm{N}$-2-phenylallylacrylamide and $N$-ethyl- $N$-2-phenylallylacrylamide in conjunction with the technique of producing alternating copolymers by use of Lewis acids; they reported that Lewis acids (namely, $\mathrm{ZnCl}_{2}$ and $\mathrm{AlEt}_{1.5} \mathrm{Cl}_{1.5}$ ) increased the rate of polymerization, although the polymers were not completely cyclized. Kakiuchi, Fukuda, and $\mathrm{Nakao}^{8}$ have also reported that the addition of Lewis acids, such as $\mathrm{ZnCl}_{2}$ and $\mathrm{SnCl}_{4}$, had little influence on the cyclopolymerization tendencies of vinyl acrylate and methacrylate.

The authors ${ }^{9}$ have previously reported that the addition of alkylaluminum chlorides to $o$ allylphenylacrylate (APA) caused an increase in its cyclopolymerization tendency, and suggested that the increase might be attributed to the intramolecular interaction between the acrylic and the allylic double bond. Therefore, it is 
interesting to see how alkylaluminum chlorides affect the cyclopolymerizations of the analogous monomers capable of forming larger rings. In the present paper, the cyclopolymerizations of 2-(o-allylphenoxy)ethyl acrylate (2-AOEA) $(\mathrm{I})$ and 4-(o-allylphenoxy)butyl acrylate (4-AOBA) (II), which give polymers containing eleven- and thirteen-membered rings, are reported.

Recently, Butler ${ }^{10}$ has communicated that an analogous monomer, $o$-(2-acryloyloxyethoxy)styrene, was cyclopolymerized by a radical initiator to polymers containing ten-membered rings.

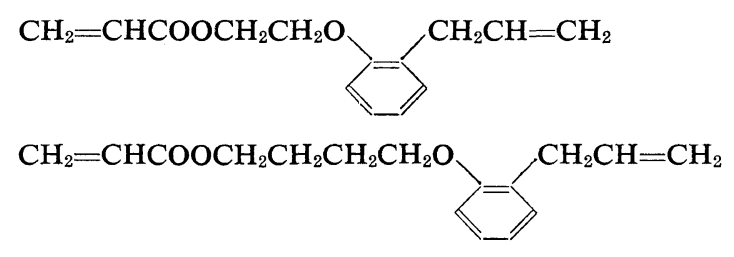

\section{EXPERIMENTAL}

\section{Monomers and Reagents}

2-(o-Allylphenoxy)ethyl Acrylate (2-AOEA). A mixture of $118 \mathrm{~g}(0.88 \mathrm{~mol})$ of $O$-allylphenol and $35 \mathrm{~g}(0.88 \mathrm{~mol})$ of sodium hydroxide in $150 \mathrm{ml}$ of dimethyl sulfoxide was gently warmed until it was thoroughly dissolved. The solution was cooled to room temperature and treated with $71 \mathrm{~g}(0.88 \mathrm{~mol})$ of ethylene chlorohydrin. After $2 \mathrm{hr}$, the mixture was diluted with an excess of water. The layer of oil was separated, washed with 10-\% aqueous sodium hydroxide, and distilled to give $113.2 \mathrm{~g}$ (72\% of the theoretical amount) of 2-(o-allylphenoxy)ethyl alcohol: bp $120-122^{\circ} \mathrm{C}(2 \mathrm{~mm})$. To a solution of $50 \mathrm{~g}(0.28 \mathrm{~mol})$ of the alcohol in $50 \mathrm{ml}$ of $N$-methylpyrrolidone and $50 \mathrm{ml}$ of carbon tetrachloride were added slowly $28 \mathrm{~g}(0.31 \mathrm{~mol})$ of acryloyl chloride through a dropping funnel at $20-25^{\circ} \mathrm{C}$. After $5 \mathrm{hr}$, the reaction mixture was washed with 10-\% aqueous sodium hydroxide, dried over anhydrous sodium sulfate, and distilled. There were obtained $48 \mathrm{~g}$ ( $78 \%$ of the theoretical amount based on the alcohol) of 2AOEA as a colorless oil: bp $132-136^{\circ} \mathrm{C}(2 \mathrm{~mm})$; $d_{4}^{15} 1.0700 ; n_{\mathrm{D}}^{20} 1.5198 ; \mathrm{NMR}\left(\mathrm{CCl}_{4}\right) \delta 3.35(\mathrm{~d}, 2$, $\left.J=6.6 \mathrm{~Hz}, \quad-\mathrm{CH}_{2} \mathrm{CH}=\right), \quad 4.09-4.21 \quad(\mathrm{~m}, \quad 2$, $\left.\mathrm{ArOC}_{2}-\right), 4.39-4.52\left(\mathrm{~m}, 2,-\mathrm{COOCH}_{2}-\right)$, 4.97 (d, $1, \quad J=11.2 \mathrm{~Hz}, \quad$ cis $-\mathrm{CH}_{2}=\mathrm{CHCH}_{2}-$ ), 5.01 (d, $1, J=16.8 \mathrm{~Hz}$, trans $-\mathrm{CH}_{2}=\mathrm{CHCH}_{2}-$ ), 5.53-6.48 (broad $\mathrm{m}, 4$, vinyl $\overline{\mathrm{H}}$ ), and 6.52$7.18(\mathrm{~m} \times 2,4$, aromatic $\mathrm{H})$.

Anal. Calcd for $\mathrm{C}_{14} \mathrm{H}_{16} \mathrm{O}_{3}: \mathrm{C}, 72.39 ; \mathrm{H}, 6.94$. Found: C, 72.53; H, 7.01.

4-(o-Allylphenoxy)butyl Acrylate (4-AOBA). The conversion of $o$-allylphenol to 4-AOBA was carried out in the manner described above, except that 4-(o-allylphenoxy)butyl alcohol was prepared from the saponification of 4-(o-allylphenoxy)butyl acetate, which was obtained by reaction of $o$-allylphenol with 4-chlorobutyl acetate. When a mixture containing $83 \mathrm{~g}(0.62$ mol) of $o$-allylphenol, $25 \mathrm{~g}(0.63 \mathrm{~mol})$ of sodium hydroxide, and $93 \mathrm{~g}(0.62 \mathrm{~mol})$ of 4-chlorobutyl acetate was subjected to the reaction sequence, there were obtained $31.3 \mathrm{~g}$ of 4 -( 0 -allylphenoxy)butyl alcohol: bp $131-141^{\circ} \mathrm{C}(2 \mathrm{~mm})$. From $31.3 \mathrm{~g}(0.15 \mathrm{~mol})$ of the alcohol and $16.5 \mathrm{~g}(0.18$ $\mathrm{mol})$ of acryloyl chloride there were obtained $28.3 \mathrm{~g} \mathrm{(79 \%}$ of the theoretical amount based on the alcohol) of 4-AOBA as a colorless oil: bp 150$155^{\circ} \mathrm{C}(3 \mathrm{~mm}) ; d_{4}^{15} 1.0381 ; n_{\mathrm{D}}^{20} 1.5131 ; \mathrm{NMR}\left(\mathrm{CCl}_{4}\right)$ $\delta 1.82$ (narrow $\left.\mathrm{m}, 4,-\mathrm{OCH}_{2} \mathrm{CH}_{2}\right), 3.36(\mathrm{~d}, 2$, $\left.J=6.6 \mathrm{~Hz},-\mathrm{CH}_{2} \mathrm{CH}=\right), 3.91\left(\mathrm{~m}, 2, \mathrm{ArOCH}_{2}-\right)$, $4.16\left(\mathrm{~m}, 2,-\mathrm{COOCH}_{2}-\right), 4.99(\mathrm{~d}, 1, J=12.8 \mathrm{~Hz}$, cis- $\left.\mathrm{CH}_{2}=\mathrm{CHCH}_{2}-\right), 5.02(\mathrm{~d}, 1, J=16.8 \mathrm{~Hz}$, trans$\mathrm{CH}_{2}=\mathrm{CHCH}_{2}-$ ), 5.63-6.49 (broad m, 4, vinyl $\mathrm{H})$, and 6.68-7.19 $(\mathrm{m} \times 2,4$, aromatic $\mathrm{H})$.

Anal. Calcd for $\mathrm{C}_{16} \mathrm{H}_{20} \mathrm{O}_{3}$ : C, 73.82; $\mathrm{H}, 7.74$. Found: C, 73.58; H, 7.75.

Alkylaluminum Chlorides. Diethylaluminum chloride, ethylaluminum sesquichloride, and ethylaluminum dichloride were prepared from triethylaluminum and aluminum trichloride by the conventional method, distilled under nitrogen atmosphere, and diluted into purified toluene.

\section{Polymerization}

Polymerizations were carried out as described in a previous paper. ${ }^{9}$ At the end of the polymerization, the reaction mixture was poured into a large amount of methanol containing 
hydrochloric acid and a white solid polymer was separated.

For the polymerizations in the presence of $\mathrm{AlEt}_{2} \mathrm{Cl}$ the reaction system was homogeneous, while a precipitate separated above an $\mathrm{Al} / \mathrm{M}$ molar ratio of 1.0 when the polymerization was carried out to high conversion. The polymers obtained were soluble in chloroform, and insoluble in benzene and carbon tetrachloride. In the presence of $\mathrm{AlEt}_{1.5} \mathrm{Cl}_{1.5}$ a somewhat sticky precipitate separated above the $\mathrm{Al} / \mathrm{M}$ molar ratio of 1.0. The polymers of 4-AOBA obtained at low conversions were soluble in chloroform, but the polymers of 2-AOEA were insoluble. In the presence of $\mathrm{AlEtCl}_{2}$ a slurry precipitate formed as the reaction proceeded and the polymers were insoluble in chloroform.

Analysis

Determination of the Extent of Cyclization in Polymers. For determination of the extent of cyclization, a calibration curve was made by plotting the mole fraction of the residual double bonds $v$ s. $D_{1640} / D_{1605}$, where $D_{1640} / D_{1605}$ is the ratio of the optical densities measured at 1640 and $1605 \mathrm{~cm}^{-1}$ by means of the nujol mull technique. The amount of residual double bonds was determined according to the elementary analysis for halogen in the polymers which resulted when the olefin was allowed to react with iodine monochloride in chloroform at $-25^{\circ} \mathrm{C}$ for $24 \mathrm{hr}$, or with bromine in chloroform at $-25^{\circ} \mathrm{C}$ for 30 sec: here the Schöniger method was used. For chloroform-insoluble polymers the extent of cyclization was estimated by extrapolating the calibration curve.

Determination of Molecular Weight. The molecular weights of soluble polymer samples were measured in chloroform at $40^{\circ} \mathrm{C}$ using a vapor pressure osmometer (Hitachi Ltd., Model 115).

Determination of the Cyclic Structure of the Polymers. A $100-\mathrm{mg}$ sample of the polymer was hydrolyzed by placing it in $5 \mathrm{ml}$ of dimethyl sulfoxide which contained $200 \mathrm{mg}$ of potassium hydroxide, and by heating at $80-100^{\circ} \mathrm{C}$ for $5 \mathrm{hr}$. The clear solution was poured into a beaker while concentrated hydrochloric acid was added and the turbid solution was dialyzed with a cellulose tube to precipitate the polymers. Then the hydrolyzed polymer was treated with diazomethane. By analysis of the IR spectra of the methylated polymers the cyclic structure of the original polymers was determined.

\section{RESULTS AND DISCUSSION}

Polymerization of 2-(o-Allylphenoxy)ethyl Acrylate (2-AOEA)

Table I. Radical polymerization of 2-(o-allylphenoxy)ethyl acrylate ${ }^{a}$

\begin{tabular}{ccccc}
\hline $\begin{array}{c}{[\mathrm{M}],} \\
\text { mol } l^{-1}\end{array}$ & $\begin{array}{c}{[\mathrm{AIBN}] /} \\
{[\mathrm{M}],} \\
\text { molar } \\
\text { ratio }\end{array}$ & $\begin{array}{c}\text { Time, } \\
\mathrm{hr}\end{array}$ & $\begin{array}{c}\text { Conver } \\
\text { sion, \% }\end{array}$ & $\begin{array}{c}\text { Extent of } \\
\text { cycli- } \\
\text { zation, } \\
\%\end{array}$ \\
\hline $\begin{array}{c}4.6 \\
\text { (Bulk) }\end{array}$ & 0.006 & 4 & 10.4 & - \\
0.8 & 0.045 & 24 & 55.8 & 43.0 \\
0.4 & 0.045 & 48 & 53.7 & 47.0 \\
\hline
\end{tabular}

a Solvent, toluene; temp, $60^{\circ} \mathrm{C}$.

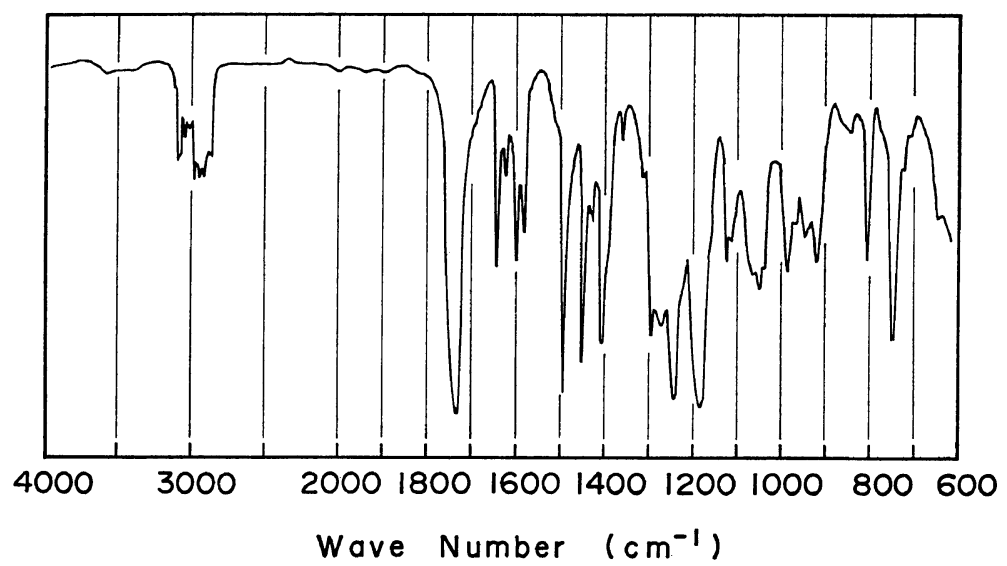

Figure 1. IR spectrum of 2-(o-allylphenoxy)ethyl acrylate. 


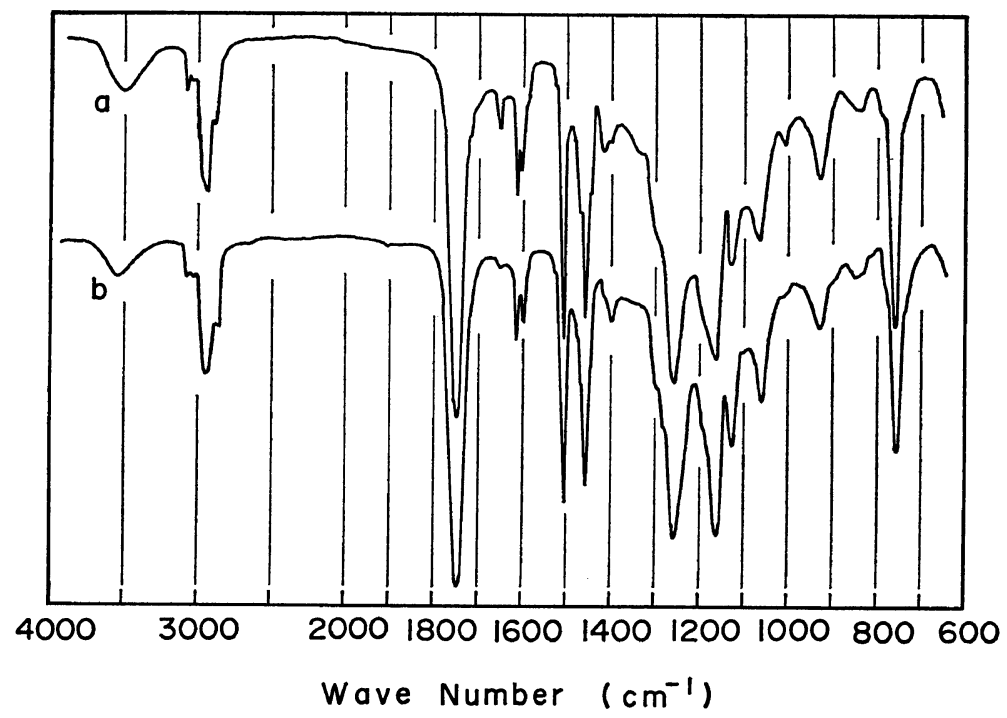

Figure 2. IR spectra of poly[2-(o-allylphenoxy)ethyl acrylate] prepared: (a) with AIBN at $60^{\circ} \mathrm{C}, f_{\mathrm{c}}=0.47$; (b) in the presence of $\mathrm{AlEtCl}_{2}, f_{\mathrm{c}}=0.95$.

The results of the conventional radical polymerization are presented in Table I. The products were colorless amorphous solids. Figures 1 and 2 show the IR spectra of the monomer and its polymer, respectively. In the spectrum of the polymer the presence of an absorption band at $1640 \mathrm{~cm}^{-1}$ is indicative of a large amount of residual double bonds which are in the form of pendant allylic double bonds, as shown from the absence of the acrylic double bonds which would show absorptions at 805 and $1405 \mathrm{~cm}^{-1}$. The polymer obtained in bulk contained a small amount of acrylic double bonds which disappeared with decreasing monomer concentration. Although a medium intensity absorption band is present at the region of the characteristic vibration $\delta \mathrm{CH}_{2}$ of the allylic double bond near $920 \mathrm{~cm}^{-1}$, the diminution of the intensities of the other characteristic bands at 1000 and $1640 \mathrm{~cm}^{-1}$ indicates that the polymerization proceeds according to a cyclization mechanism. The extent of cyclization was $47 \%$ at the monomer concentration of $0.4 \mathrm{~mol} l^{-1}$.

Some results of the polymerization in the presence of alkylaluminum chlorides at an $\mathrm{Al} / \mathrm{M}$ molar ratio of 1.0 are shown in Table II. Spontaneous polymerization, i.e., in the absence of a free-radical initiator, occurred and the ad-
Table II. Polymerization of 2-(o-allylphenoxy)ethyl acrylate in the presence of alkylaluminum chlorides ${ }^{\mathrm{a}}$

\begin{tabular}{lccc}
\hline $\begin{array}{c}\text { Alkylaluminum } \\
\text { chloride }\end{array}$ & $\begin{array}{c}\text { [AIBN], } \\
\mathrm{mmol} l\end{array} l^{-1}$ & $\begin{array}{c}\text { Time, } \\
\mathrm{hr}\end{array}$ & $\begin{array}{c}\text { Conversion, } \\
\%\end{array}$ \\
\hline $\mathrm{AlEt}_{2} \mathrm{Cl}$ & 0 & 24 & 27.3 \\
& 5.06 & 0.5 & 15.2 \\
& 5.06 & 1 & 31.3 \\
& 5.06 & 3 & 66.9 \\
\hline $\mathrm{AlEt}_{1.5} \mathrm{Cl}_{1.5}$ & 0 & 24 & 23.1 \\
& 5.06 & 0.5 & 24.5 \\
& 5.06 & 1 & 51.0 \\
& 5.06 & 3 & 93.3 \\
\hline $\mathrm{AlEtCl}_{2}$ & 0 & 24 & 8.6 \\
& 5.06 & 0.5 & 10.8 \\
& 5.06 & 1 & 25.8 \\
& 5.06 & 3 & 95.8 \\
\hline
\end{tabular}

a Solvent, toluene; $[\mathrm{M}], 0.46 \mathrm{~mol} l^{-1} ; \mathrm{Al} / \mathrm{M}$ molar ratio, 1.0 ; temp, $40^{\circ} \mathrm{C}$.

dition of the initiator induced a more rapid polymerization. This polymerization, however, was slower than that of APA which occurred with a moderate rate even in the absence of the initiator, as previously reported. ${ }^{9}$ The $\mathrm{Al} / \mathrm{M}$ molar ratio can influence the polymerization rate. Figure 3 shows that the rate increases with increasing ratio. The accelerating effect 


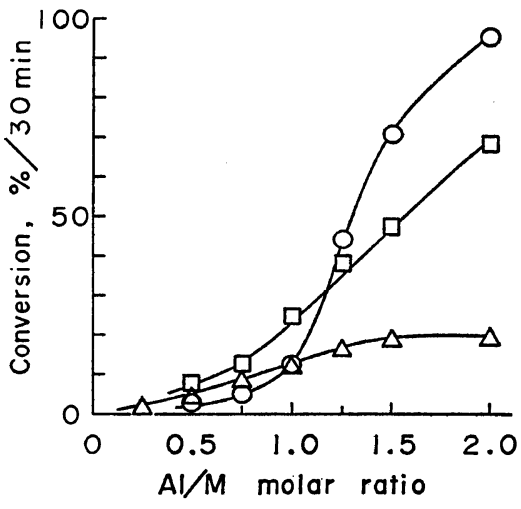

Figure 3. Effect of $A 1 / M$ molar ratio on the rate of polymerization of 2-AOEA: $(\triangle)$ in the presence of $\mathrm{AlEt}_{2} \mathrm{Cl} ;(\square)$ in the presence of $\mathrm{AlEt}_{1.5} \mathrm{Cl}_{1.5}$; $(O)$ in the presence of $\mathrm{AlEtCl}_{2}$.

for the rate increased in the order of $\mathrm{AlEt}_{2} \mathrm{Cl}<$ $\mathrm{AlEt}_{1.5} \mathrm{Cl}_{1.5}<\mathrm{AlEtCl}_{2}$. This increase appears to correspond to the increasing acidity of the alkylaluminum chlorides as Lewis acids.

The IR spectrum of the polymer obtained by the polymerization in the presence of $\mathrm{AlEtCl}_{2}$ is shown in Figure 2. A comparison of the spectra of polymers prepared with different conditions shows no substantial differences between them, except that the intensities of the absorptions due to the residual allylic double bond considerably diminished in the presence of $\mathrm{AlEtCl}_{2}$.

The effects of alkylaluminum chlorides on the extent of cyclization are given in Tables III, IV, and $\mathrm{V}$. In the presence of $\mathrm{AlEt}_{2} \mathrm{Cl}$ the extent

Table III. Effect of $\mathrm{A} / \mathrm{M}$ molar ratio on the polymerization of 2-(o-allylphenoxy)ethyl acrylate in the presence of $\mathrm{AlEt}_{2} \mathrm{Cl}^{\mathrm{a}}$

\begin{tabular}{lrrcc}
\hline $\begin{array}{c}\text { Al/M, } \\
\text { molar } \\
\text { ratio }\end{array}$ & $\begin{array}{c}\text { Time, } \\
\text { min }\end{array}$ & $\begin{array}{c}\text { Conver- } \\
\text { sion, \% }\end{array}$ & $\begin{array}{c}\text { Extent of } \\
\text { cycli- } \\
\text { zation, \% }\end{array}$ & $\begin{array}{c}\text { Molecular } \\
\text { weight } \\
\text { of } \\
\text { polymer }\end{array}$ \\
\hline 0.25 & 220 & 9.4 & 85.0 & - \\
0.5 & 120 & 17.5 & 85.0 & 7500 \\
0.75 & 75 & 10.6 & 87.5 & 7200 \\
1.0 & 40 & 13.9 & 88.0 & 5400 \\
1.25 & 25 & 12.8 & 89.5 & 6500 \\
1.5 & 20 & 15.9 & 90.5 & 5200 \\
2.0 & 15 & 17.8 & 90.5 & 3600 \\
\hline
\end{tabular}

Solvent, toluene; [M], $0.44 \mathrm{~mol}^{-1}$; [AIBN], 4.84 $\mathrm{mmol} l^{-1}$, temp, $40^{\circ} \mathrm{C}$.
Table IV. Effect of $\mathrm{Al} / \mathrm{M}$ molar ratio on the polymerization of 2-(o-allylphenoxy)ethyl acrylate in the presence of $\mathrm{AlEt}_{1.5} \mathrm{Cl}_{1.5^{\mathrm{a}}}$

\begin{tabular}{lccc}
\hline $\begin{array}{c}\text { Al/M, } \\
\text { molar } \\
\text { ratio }\end{array}$ & $\begin{array}{c}\text { Time, } \\
\text { min }\end{array}$ & $\begin{array}{c}\text { Conversion, } \\
\%\end{array}$ & $\begin{array}{c}\text { Extent of } \\
\text { cyclization, } \\
\%\end{array}$ \\
\hline 0.5 & 45 & $10.1^{\mathrm{b}}$ & 88.5 \\
0.75 & 30 & 15.1 & 89.0 \\
1.0 & 20 & 18.1 & 90.0 \\
1.25 & 10 & 15.8 & 92.5 \\
1.5 & 8 & 17.0 & 95.0 \\
2.0 & 5 & 18.0 & 94.0 \\
\hline
\end{tabular}

a Solvent, toluene; [M], $0.44 \mathrm{~mol} \mathrm{l}^{l^{-1}}$; [AIBN], 4.84 $\mathrm{mmol} l^{-1}$; temp, $40^{\circ} \mathrm{C}$.

b Molecular weight of polymer, 9400 .

Table V. Effect of Al/M molar ratio on the polymerization of 2-(o-allylphenoxy)ethyl acrylate in the presence of $\mathrm{AlEtCl}_{2} \mathrm{a}$

\begin{tabular}{lccc}
\hline $\begin{array}{c}\text { Al/M, } \\
\text { molar } \\
\text { ratio }\end{array}$ & $\begin{array}{c}\text { Time, } \\
\text { min }\end{array}$ & $\begin{array}{c}\text { Conversion, } \\
\%\end{array}$ & $\begin{array}{c}\text { Extent of } \\
\text { cyclization, } \\
\%\end{array}$ \\
\hline 0.5 & 45 & 7.4 & 87.0 \\
0.75 & 30 & 7.5 & 88.5 \\
1.0 & 20 & 12.6 & 93.5 \\
1.25 & 10 & 20.6 & 94.5 \\
1.5 & 8 & 20.9 & 94.0 \\
2.0 & 5 & 18.4 & 96.0 \\
\hline
\end{tabular}

a Solvent, toluene; [M], $0.44 \mathrm{~mol} l^{-1}$; [AIBN], 4.84 $\mathrm{mmol} l^{-1}$; temp, $40^{\circ} \mathrm{C}$.

of cyclization increased from $85 \%$ at the $\mathrm{Al} / \mathrm{M}$ molar ratio of 0.25 to $90.5 \%$ at the ratio of 2.0; however, the variation was small. When this result is compared with that of APA, there is a characteristic difference in the effects of $\mathrm{AlEt}_{2} \mathrm{Cl}$. As for the polymerization of APA, the rate of polymerization and the extent of cyclization attained a maximum at the $\mathrm{Al} / \mathrm{M}$ molar ratio in the range $0.2-0.3$. In the presence of $\mathrm{AlEt}_{1.5} \mathrm{Cl}_{1.5}$ and $\mathrm{AlEtCl}_{2}$, as the $\mathrm{Al} / \mathrm{M}$ molar ratio increased, the extent of cyclization increased to $95 \%$ for $\mathrm{AlEt}_{1.5} \mathrm{Cl}_{1.5}$ and to $96 \%$ for $\mathrm{AlEtCl}_{2}$, but the increases were very small and almost leveled off above the ratio of 1.0. The increasing order of the effects of the alkylaluminum chlorides agrees with that for the rates of polymerization.

Polymerization of 4-(o-Allylphenoxy)butyl Acrylate (4- $A O B A)$

The results of the conventional radical poly- 
Table VI. Radical polymerization of 4-(o-allylphenoxy) butyl acrylate ${ }^{a}$

\begin{tabular}{ccccc}
\hline $\begin{array}{c}{[\mathrm{M}],} \\
\text { mol } l^{-1}\end{array}$ & $\begin{array}{c}\text { [AIBN]/ } \\
{[\mathrm{M}]} \\
\text { molar } \\
\text { ratio }\end{array}$ & $\begin{array}{c}\text { Time, } \\
\text { hr }\end{array}$ & $\begin{array}{c}\text { Conver- } \\
\text { sion, } \%\end{array}$ & $\begin{array}{c}\text { Extent of } \\
\text { cycli- } \\
\text { zation, } \\
\%\end{array}$ \\
\hline $\begin{array}{c}4.0 \\
\text { (Bulk) }\end{array}$ & 0.007 & 4 & 8.4 & - \\
0.8 & 0.051 & 24 & 48.9 & 33.0 \\
0.4 & 0.051 & 48 & 45.0 & 36.0 \\
\hline
\end{tabular}

a Solvent, toluene; temp, $60^{\circ} \mathrm{C}$. merization are presented in Table VI. All the products were somewhat sticky semi-solids. Figures 4 and 5 show the IR spectra of the monomer and its polymer, respectively. Although a small amount of acrylic double bonds remained after the polymerization in bulk, all the acrylic double bonds and a part of the allylic double bonds were consumed by that in dilute solution. The amount of residual double bonds was estimated by the absorption bands at 920 and 1640 $\mathrm{cm}^{-1}$, characteristic of the allylic double bond. The extent of cyclization was $37 \%$ at the mono-

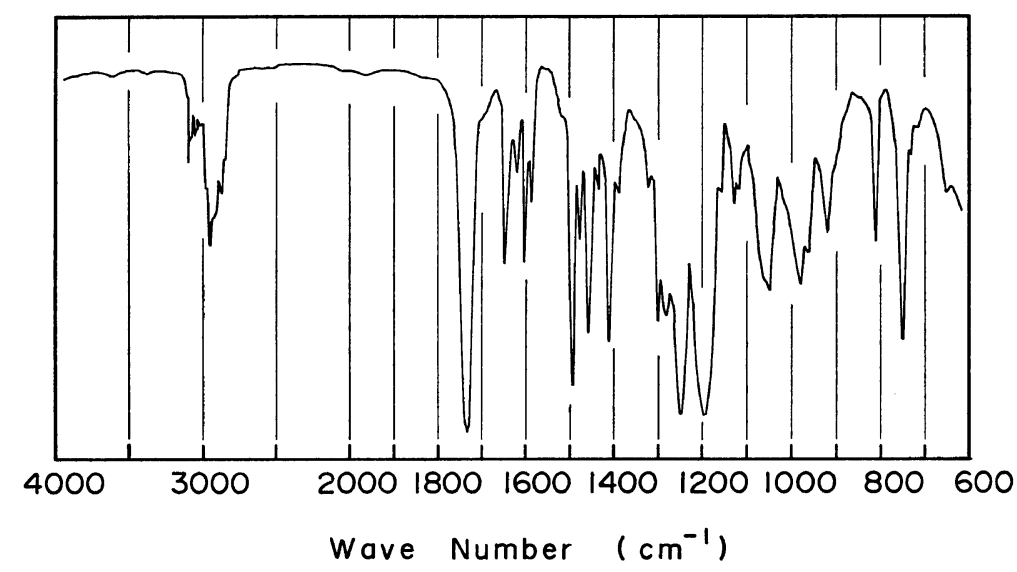

Figure 4. IR spectrum of 4-(o-allylphenoxy)butyl acrylate.

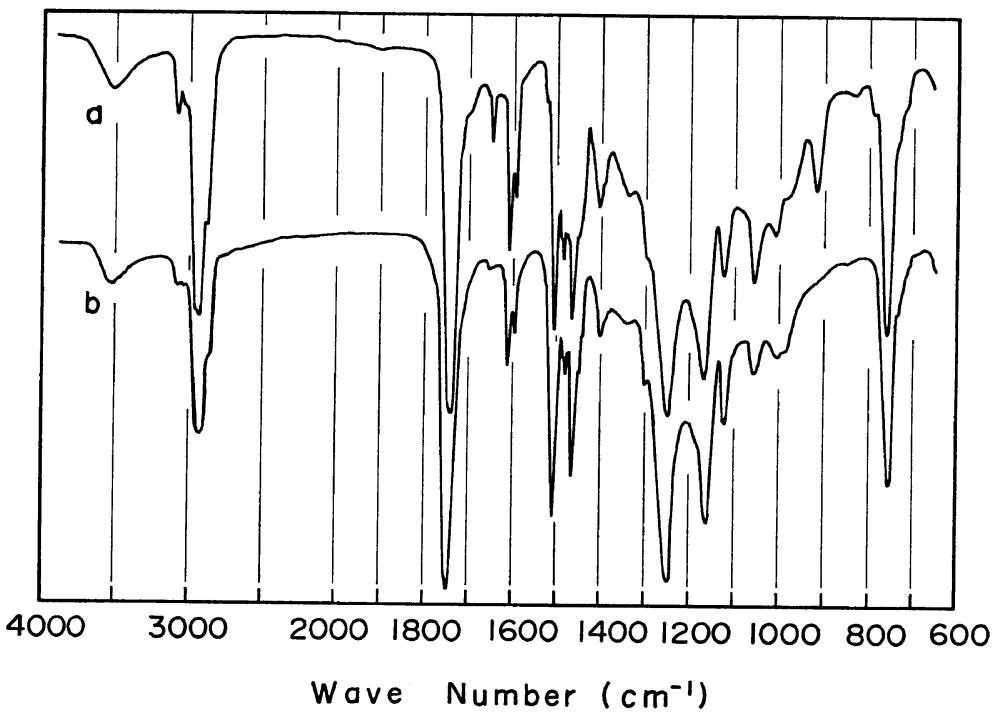

Figure 5. IR spectra of poly[4-(o-allylphenoxy)butyl acrylate]prepared: (a) with AIBN at $60^{\circ} \mathrm{C}, f_{\mathrm{c}}=0.36$; (b) in the presence of $\mathrm{AlEtCl}_{2}, f_{\mathrm{c}}=0.92$. 
Table VII. Polymerization of 4-(o-allylphenoxy)butyl acrylate in the presence of alkylaluminum chlorides $^{\mathrm{a}}$

\begin{tabular}{lcrc}
\hline $\begin{array}{c}\text { Alkylaluminum } \\
\text { chloride }\end{array}$ & $\begin{array}{c}\text { [AIBN], } \\
\mathrm{mmol} l^{-1}\end{array}$ & $\begin{array}{c}\text { Time, } \\
\mathrm{hr}\end{array}$ & $\begin{array}{c}\text { Conversion, } \\
\%\end{array}$ \\
\hline $\mathrm{AlEt}_{2} \mathrm{Cl}$ & 0 & 24 & 4.8 \\
& 5.72 & 1 & 12.6 \\
& 5.72 & 2 & 23.1 \\
& 5.72 & 4 & 48.3 \\
\hline $\mathrm{AlEt}_{1.5} \mathrm{Cl}_{1.5}$ & 0 & 24 & 16.5 \\
& 5.72 & 1 & 10.5 \\
& 5.72 & 2 & 19.4 \\
& 5.72 & 4 & 51.5 \\
\hline $\mathrm{AlEtCl}_{2}$ & 0 & 24 & 4.4 \\
& 5.72 & 1 & 10.7 \\
& 5.72 & 2 & 21.3 \\
& 5.72 & 4 & 43.4
\end{tabular}

a Solvent, toluene; [M], $0.44 \mathrm{~mol}^{l^{-1}} ; \mathrm{Al} / \mathrm{M}$ molar ratio, 1.0 ; temp, $40^{\circ} \mathrm{C}$.

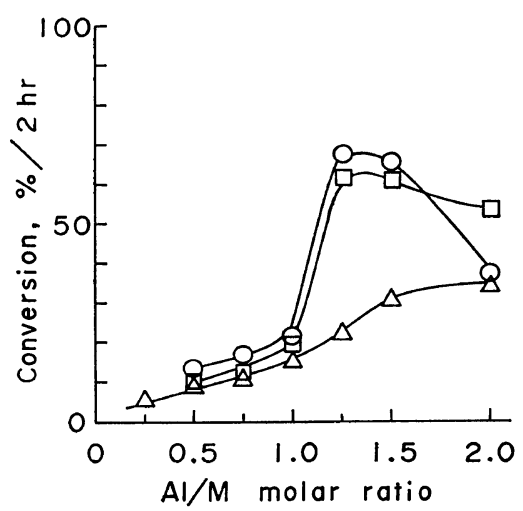

Figure 6. Effect of $\mathrm{Al} / \mathrm{M}$ molar ratio on the rate of polymerization of 4-AOBA: $(\triangle)$ in the presence of $\mathrm{AlEt}{ }_{2} \mathrm{Cl} ;(\square)$ in the presence of $\mathrm{AlEt}_{1.5} \mathrm{Cl}_{1.5}$; $(\bigcirc)$ in the presence of $\mathrm{AlEtCl}_{2}$.

mer concentration of $0.4 \mathrm{~mol} l^{-1}$.

Some results of the polymerization in the presence of alkylaluminum chlorides at the $\mathrm{Al} / \mathrm{M}$ molar ratio of 1.0 are shown in Table VII. Spontaneous polymerization also occurred, but the addition of the free-radical initiator was required for a moderate rate of polymerization. Since the polymerization of 4-AOBA is slower, and that of APA faster, than that of 2-AOEA, the reactivities decrease upon increasing the number of atoms between the acrylic and the allylic double bond in the molecule. Figure 6 shows the effect of the $\mathrm{Al} / \mathrm{M}$ molar ratio on the rate of polymerization. As the ratio increased, the rate reached a maximum value, and then slightly decreased as the ratio was increased further.

The IR spectrum of the polymer prepared in the presence of $\mathrm{AlEtCl}_{2}$ is shown in Figure 5. IR spectral analysis shows that the residual double bond is in the form of the pendant allylic double bond only and that the amount is far smaller than that in the radical polymer.

The effects of alkylaluminum chlorides on the extent of cyclization are given in Tables VIII, $\mathrm{IX}$, and $\mathrm{X}$. In the presence of $\mathrm{AlEt}_{2} \mathrm{Cl}$ the extent of cyclization slightly increased, from $83 \%$ at the $\mathrm{Al} / \mathrm{M}$ molar ratio of 0.25 to $89 \%$ at the

Table VIII. Effect of $\mathrm{Al} / \mathrm{M}$ molar ratio on the polymerization of 4-(o-allylphenoxy)butyl acrylate in the presence of $\mathrm{AlEt}_{2} \mathrm{Cl}^{\mathrm{a}}$

\begin{tabular}{lcccc}
\hline $\begin{array}{c}\text { Al/M, } \\
\text { molar } \\
\text { ratio }\end{array}$ & $\begin{array}{c}\text { Time, } \\
\text { min }\end{array}$ & $\begin{array}{c}\text { Conver- } \\
\text { sion, \% }\end{array}$ & $\begin{array}{c}\text { Extent of } \\
\text { cycliza- } \\
\text { tion, \% }\end{array}$ & $\begin{array}{c}\text { Molecular } \\
\text { weight } \\
\text { of } \\
\text { polymer }\end{array}$ \\
\hline 0.25 & 260 & 8.4 & 83.0 & - \\
0.5 & 180 & 9.8 & 85.5 & 9800 \\
0.75 & 120 & 9.4 & 86.0 & 14600 \\
1.0 & 90 & 8.9 & 87.0 & 9900 \\
1.25 & 60 & 8.1 & 88.0 & - \\
1.5 & 45 & 9.4 & 88.5 & 8100 \\
2.0 & 30 & 10.9 & 89.0 & 5800 \\
\hline
\end{tabular}

a Solvent, toluene; [M], $0.41 \mathrm{~mol} \mathrm{l}^{-1}$; [AIBN], 5.33 mmol $l^{-1} ;$ temp, $40^{\circ} \mathrm{C}$.

Table IX. Effect of $\mathrm{Al} / \mathrm{M}$ molar ratio on the polymerization of 4-( $o$-allylphenoxy)butyl acrylate in the presence of $\mathrm{AlEt}_{1.5} \mathrm{Cl}_{1.5}{ }^{\mathrm{a}}$

\begin{tabular}{lcccc}
\hline $\begin{array}{l}\text { Al/M, } \\
\text { molar } \\
\text { ratio }\end{array}$ & $\begin{array}{c}\text { Time, } \\
\text { min }\end{array}$ & $\begin{array}{c}\text { Conver- } \\
\text { sion, \% }\end{array}$ & $\begin{array}{c}\text { Extent of } \\
\text { cycliza } \\
\text { tion, } \%\end{array}$ & $\begin{array}{c}\text { Molecular } \\
\text { weight } \\
\text { of } \\
\text { polymer }\end{array}$ \\
\hline 0.5 & 90 & 6.9 & 87.5 & 19000 \\
0.75 & 60 & 8.6 & 88.5 & 18000 \\
1.0 & 45 & 9.4 & 90.5 & 14500 \\
1.25 & 30 & 12.4 & 91.5 & 15700 \\
1.5 & 20 & 12.9 & 91.0 & 12300 \\
2.0 & 15 & 8.7 & 90.0 & - \\
\hline
\end{tabular}

a Solvent, toluene; [M], $0.41 \mathrm{~mol} l^{-1}$; [AIBN], 5.33 $\mathrm{mmol} l^{-1} ;$ temp, $40^{\circ} \mathrm{C}$. 
Table $\mathbf{X}$. Effect of $\mathrm{Al} / \mathrm{M}$ molar ratio on the polymerization of 4-(o-allylphenoxy)butyl acrylate in the presence of $\mathrm{AlEtCl}_{2}{ }^{\mathrm{a}}$

\begin{tabular}{lccc}
\hline $\begin{array}{c}\text { Al/M, } \\
\text { molar } \\
\text { ratio }\end{array}$ & $\begin{array}{c}\text { Time, } \\
\text { min }\end{array}$ & $\begin{array}{c}\text { Conversion, } \\
\%\end{array}$ & $\begin{array}{c}\text { Extent of } \\
\text { cyclization, } \\
\%\end{array}$ \\
\hline 0.5 & 60 & 5.2 & 90.5 \\
0.75 & 45 & 5.5 & 92.0 \\
1.0 & 30 & 7.1 & 93.0 \\
1.25 & 20 & 9.1 & 92.0 \\
1.5 & 15 & 7.2 & 91.0 \\
2.0 & 20 & 6.0 & 88.0
\end{tabular}

a Solvent, toluene; [M], $0.41 \mathrm{~mol} l^{-1} ;$ [AIBN], 5.33 $\mathrm{mmol} l^{-1}$; temp, $40^{\circ} \mathrm{C}$.

ratio of 2.0. In the presence of $\mathrm{AlEt}_{1.5} \mathrm{Cl}_{1.5}$ and $\mathrm{AlEtCl}_{2}$, as the ratio increased, the extent of cyclization reached a maximum value below the ratio of 2.0: $91.5 \%$ at the ratio of 1.25 for $\mathrm{AlEt}_{1.5} \mathrm{Cl}_{1.5} ; 93 \%$ at the ratio of 1.0 for $\mathrm{AlEtCl}_{2}$. These features are similar to the effects on the rate of polymerization. The cyclopolymerization tendency slightly decreased upon increasing the number of atoms between two double bonds, in the order of APA $>2$-AOEA $>4$-AOBA. Even for 4-AOBA, however, the extent of cyclization was as high as $98 \%$ at conversions higher than $60 \%$.

\section{Dependence of the Extent of Cyclization on the Monomer Concentration}

For the cyclopolymerization of APA in the presence of $\mathrm{AlEt}_{2} \mathrm{Cl}$, the extent of cyclization depended on the monomer concentration. The following equation, which relates the fraction of cyclized unit $f_{\mathrm{c}}$ to the monomer concentration [M], has been derived by Roovers and Smets ${ }^{11}$

$$
\frac{1}{f_{\mathrm{c}}}=1+\frac{k_{\mathrm{p}}}{k_{\mathrm{c}}}[\mathrm{M}]
$$

where $k_{\mathrm{p}}$ and $k_{\mathrm{c}}$ are the rate constants of the intermolecular linear propagation and the intramolecular cyclization, respectively. A plot of $1 / f_{\mathrm{c}} v s$. [M] resulted in a slope with a value of $0.62 \mathrm{lmol}^{-1}$. On the other hand, in the presence of $\mathrm{AlEt}_{1.5} \mathrm{Cl}_{1.5}$ and $\mathrm{AlEtCl}_{2}$, the extent of cyclization was practically independent of the monomer concentration; this means that an intramolecular interaction between the acrylic and the allylic double bond in the polymerization process might be the driving force for the higher cyclopolymerization tendency.

Therefore, the dependence on monomer concentration for the polymerizations of 2-AOEA and 4-AOBA was examined. The data of the cyclopolymerization at $20^{\circ} \mathrm{C}$ are given in Tables $\mathrm{XI}$ and XII. As the monomer concentration decreased, the reaction systems became heterogeneous and the extent of cyclization in the polymers obtained increased. These features show that the solubilities of the polymers decrease with increasing extent of cyclization. As shown in Figures 7 and 8, the experimental data are well fitted by a straight line when plotted $1 / f_{\mathrm{c}}$ vs. [M]. For the polymerizations of both monomers in the presence of $\mathrm{AlEtCl}_{2}$, the plots satisfy eq 1 and give an intercept at infinite dilution to complete cyclization: the ratio of $k_{\mathrm{p}} / k_{\mathrm{c}}=0.17 l \mathrm{~mol}^{-1}$ for 2-AOEA and $0.27 l \mathrm{~mol}^{-1}$ for 4-AOBA. In the presence of $\mathrm{AlEt}_{2} \mathrm{Cl}$ and $\mathrm{AlEt}_{1.5} \mathrm{Cl}_{1.5}$, the slopes are much the same as that for $\mathrm{AlEtCl}_{2}$, but the intercepts fail to pass through 1.0. The deviations from eq 1 are smaller for 4-AOBA than for 2-AOEA.

Table XI. Effect of monomer concentration on the polymerization of 2-(o-allylphenoxy)ethyl acrylate in the presence of alkylaluminum chlorides ${ }^{a}$

\begin{tabular}{|c|c|c|c|c|}
\hline $\begin{array}{l}{[\mathrm{M}]} \\
\mathrm{mol} l^{-1}\end{array}$ & Time, & $\begin{array}{l}\text { Conver- } \\
\text { sion, } \%\end{array}$ & $\begin{array}{c}\text { Extent } \\
\text { of cycli- } \\
\text { zation, } \\
\%\end{array}$ & $\begin{array}{c}\text { Reaction } \\
\text { system }\end{array}$ \\
\hline \multicolumn{5}{|l|}{$\mathrm{AlEt}_{2} \mathrm{Cl}$} \\
\hline 1.85 & 0.7 & 5.1 & 70.5 & Homogeneous \\
\hline 0.79 & 1.2 & 5.2 & 81.0 & Homogeneous \\
\hline 0.39 & 1.7 & 5.7 & 86.5 & Homogeneous \\
\hline 0.19 & 2.3 & 5.8 & 90.0 & $\begin{array}{l}\text { Slightly } \\
\text { heterogeneous }\end{array}$ \\
\hline
\end{tabular}

\begin{tabular}{ccrrl}
\hline $\mathrm{AlEt}_{1.5} \mathrm{Cl}_{1.5}$ & & & \\
1.89 & 0.5 & 11.5 & 68.0 & Homogeneous \\
0.80 & 0.75 & 10.1 & 85.0 & Homogeneous \\
0.39 & 1.0 & 9.2 & 89.5 & Heterogeneous \\
0.19 & 1.5 & 8.2 & 93.5 & Heterogeneous \\
\hline
\end{tabular}

\begin{tabular}{lllll}
\hline $\mathrm{AlEtCl}_{2}$ & & & & \\
1.86 & 0.5 & 13.3 & 76.0 & Homogeneous \\
0.79 & 0.75 & 10.1 & 89.0 & Heterogeneous \\
0.39 & 1.0 & 10.8 & 93.5 & Heterogeneous \\
0.19 & 1.5 & 14.1 & 96.5 & Heterogeneous \\
\hline
\end{tabular}

a Solvent, toluene; $\mathrm{Al} / \mathrm{M}$ molar ratio, $1.25 ; \mathrm{AIBN} / \mathrm{M}$ molar ratio, 0.011 ; temp, $20^{\circ} \mathrm{C}$. 
Table XII. Effect of monomer concentration on the polymerization of 4-(o-allylphenoxy)butyl acrylate in the presence of alkylaluminum chlorides ${ }^{\mathrm{a}}$

\begin{tabular}{|c|c|c|c|c|}
\hline $\begin{array}{l}{[\mathrm{M}]} \\
\operatorname{mol} l^{-1}\end{array}$ & $\underset{\mathrm{hr}}{\mathrm{Time}}$ & $\begin{array}{l}\text { Conver- } \\
\text { sion, } \%\end{array}$ & $\begin{array}{c}\text { Extent } \\
\text { of cycli- } \\
\text { zation, } \\
\%\end{array}$ & $\begin{array}{c}\text { Reaction } \\
\text { system }\end{array}$ \\
\hline
\end{tabular}

\begin{tabular}{lllll}
\hline $\mathrm{AlEt}_{2} \mathrm{Cl}$ & & & & \\
1.77 & 2 & 7.0 & 68.5 & Homogeneous \\
0.79 & 3 & 7.2 & 79.0 & Homogeneous \\
0.39 & 5 & 8.3 & 87.0 & Homogeneous \\
0.19 & 8 & 8.2 & 92.5 & Homogeneous \\
\hline
\end{tabular}

\begin{tabular}{|c|c|c|c|c|}
\hline \multicolumn{5}{|c|}{$\mathrm{AlEt}_{1.5} \mathrm{Cl}_{1.5}$} \\
\hline 1.76 & 1 & 6.4 & 69.5 & Homogeneous \\
\hline 0.77 & 2 & 7.3 & 80.5 & Homogeneous \\
\hline 0.39 & 3 & 6.3 & 90.0 & Heterogeneous \\
\hline 0.19 & 5 & 6.3 & 94.0 & Heterogeneous \\
\hline \multicolumn{5}{|c|}{$\mathrm{AlEtCl}_{2}$} \\
\hline 1.72 & 1 & 10.0 & 65.0 & Homogeneous \\
\hline 0.77 & 2 & 12.4 & 83.0 & Homogeneous \\
\hline 0.39 & 3 & 11.3 & 91.0 & Heterogeneous \\
\hline 0.19 & 5 & 12.0 & 96.0 & Heterogeneous \\
\hline
\end{tabular}

a Solvent, toluene; $\mathrm{Al} / \mathrm{M}$ molar ratio, 1.25; $\mathrm{AIBN} /$ $\mathrm{M}$ molar ratio, 0.013 ; temp, $20^{\circ} \mathrm{C}$.

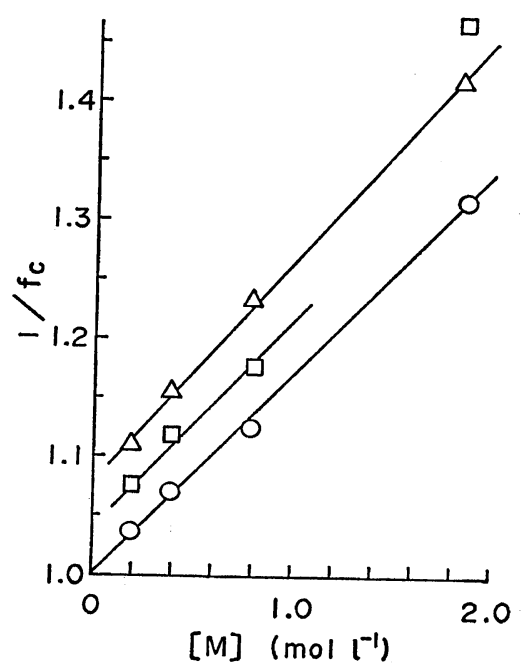

Figure 7. Representation of experimental data for the polymerization of 2-(o-allylphenoxy)ethyl acrylate according to eq 1: $(\triangle)$ in the presence of $\mathrm{AlEt}{ }_{2} \mathrm{Cl}$; $(\square)$ in the presence of $\mathrm{AlEt}_{1.5} \mathrm{Cl}_{1.5}$; (O) in the presence of $\mathrm{AlEtCl}_{2}$.

The values obtained for $k_{\mathrm{p}} / k_{\mathrm{c}}$ are comparable to a value of $0.17 \mathrm{lmol}^{-1}$ at $35^{\circ} \mathrm{C}$ for acrylic anhydride ${ }^{12}$, which is a symmetrical 1,6-diene

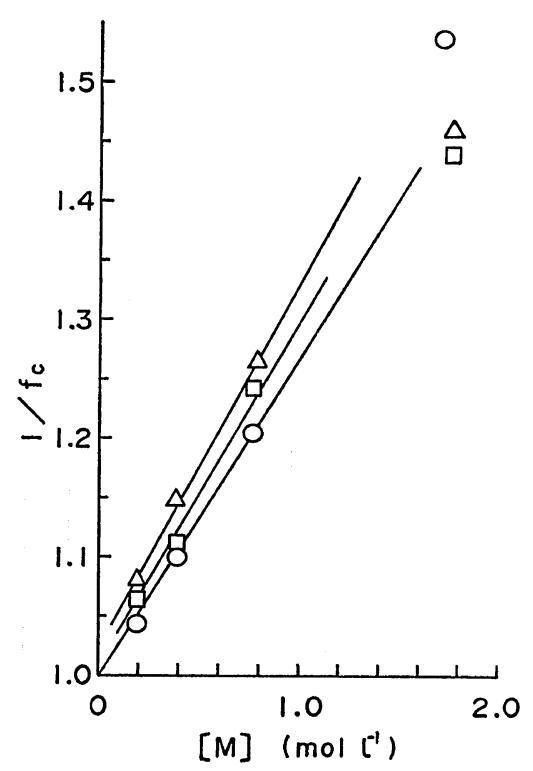

Figure 8. Representation of the experimental data for the polymerization of 4-(o-allylphenoxy)butyl acrylate according to eq $1:(\triangle)$ in the presence of $\mathrm{AlEt}_{2} \mathrm{Cl} ;(\square)$ in the presence of $\mathrm{AlEt}_{1.5} \mathrm{Cl}_{1.5}$; $(\mathrm{O})$ in the presence of $\mathrm{AlEtCl}_{2}$.

forming five- and six-membered rings. The addition of alkylaluminum chlorides would cause the formation of the intramolecular interaction in the polymerization process to give a marked increase in the cyclopolymerization tendency of 2-AOEA and 4-AOBA.

\section{Structure of the Cyclized Polymers}

In the cyclopolymerizations of 2-AOEA and 4-AOBA there are the possibilities of the formation of polymers containing ten- or elevenmembered rings and twelve- and thirteen-membered rings, respectively. The cyclized polymer is transformed into the methylated polymer corresponding to the alternating copolymer of methyl acrylate and $o$-alkoxyallylbenzene by means of the hydrolysis and the diazomethane treatment. Thus the determination of the structure of the cyclized polymer can be reduced to analyzing the mode of addition in the methylated polymer. Although the head-to-tail additions predominate in conventional polymerizations, several examples of a polymer with a structure consisting of essentially all head-to-head units are found in the literature: poly(vinyl chloride), ${ }^{13}$ poly(vinylidene 
chloride), ${ }^{14}$ poly(methyl acrylate), ${ }^{15,16}$ and poly(methyl cinnamate). ${ }^{17}$ It has been reported that these head-to-head polymers have IR absorption characteristics different with those of their headto-tail isomers. The methylated polymer derived from APA accurately corresponded to the alternating copolymer with head-to-tail units, which was prepared from the copolymerization of methyl acrylate and $o$-methoxyallylbenzene in the presence of alkylaluminum chlorides; this means that APA polymerized to give polymers containing eight-membered rings.

Therefore, the same treatments were applied to the cyclized polymers of 2-AOEA and 4-AOBA. These polymers were not hydrolyzed with $10-\%$ methanolic potassium hydroxide, which was used for the cyclized polymer of APA, but were entirely hydrolyzed with potassium hydroxide in dimethyl sulfoxide. The polymer of 2-AOEA was hydrolyzed in less than $2 \mathrm{hr}$, while that of

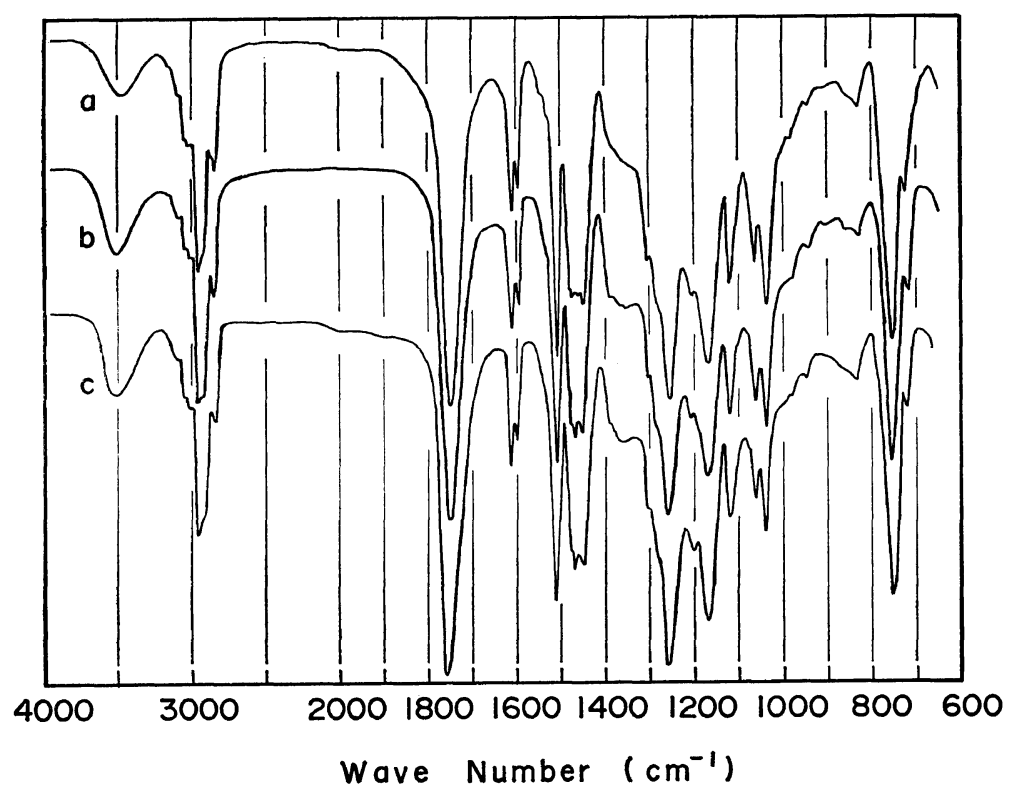

Figure 9. IR spectra of the methylated polymers derived from the following cyclized polymers: (a) poly(o-allylphenyl acrylate); (b) poly[2-(o-allylphenoxy)ethyl] acrylate; (c) poly[4(o-allylphenoxy)butyl acrylate].

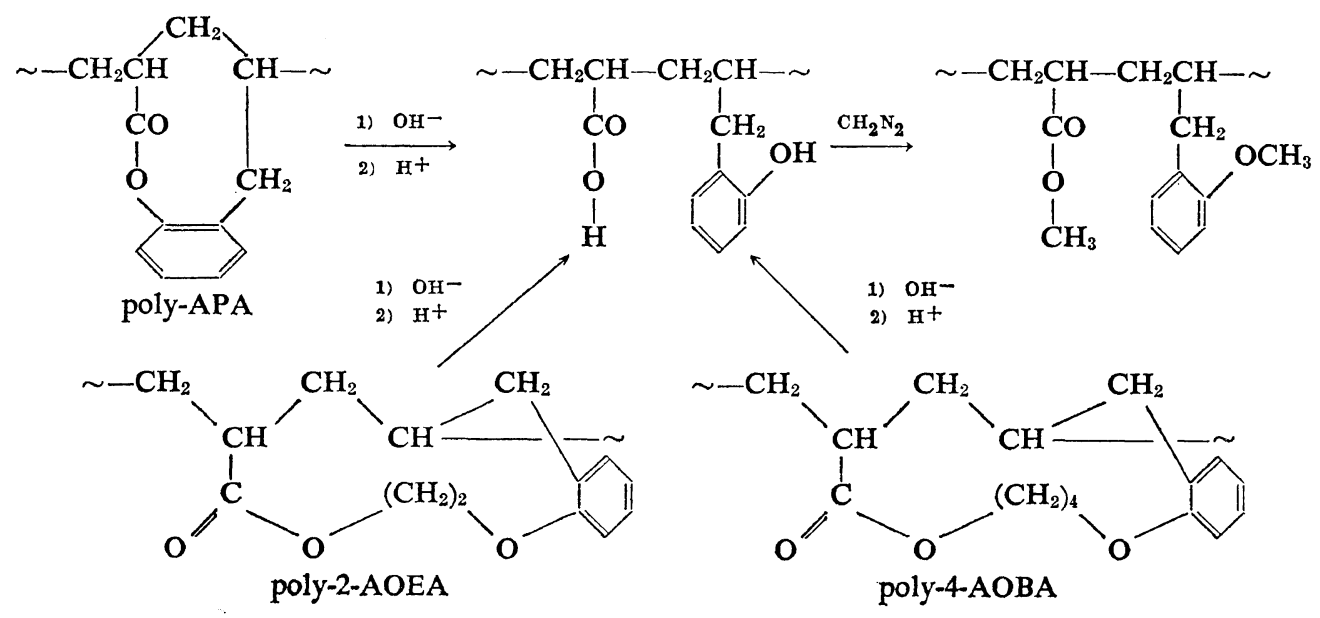


4-AOBA required $4 \mathrm{hr}$. IR spectra of the methylated polymers derived from APA, 2-AOEA, and 4-AOBA are shown in Figure 9. The spectra of the three samples are superimposable, except that the intensities of the absorption bands at 1465,2930 , and $2960 \mathrm{~cm}^{-1}$ are slightly different. Consequently, in the base-catalyzed hydrolysis the cleavage of lactone rings and the elimination of ethoxy or butoxy groups took place and all the hydrolyzed polymers were identical in structure, as shown in eq 2 . It is concluded that 2-AOEA and 4-AOBA polymerized to form eleven- and thirteen-membered rings, respectively.

\section{REFERENCES}

1. W. E. Gibbs and J. M. Barton in "Vinyl polymerization," Vol. 1, Part 1, G. H. Ham, Ed., Marcel Dekker, Inc., New York, N.Y., 1967, p 59.

2. C. S. Marvel and J. K. Stille, J. Amer. Chem. Soc., 80, 1740 (1958).

3. C. S. Marvel and W. E. Garrison, Jr., ibid., 81, 4737 (1959).

4. G. B. Butler, J. Polym. Sci., 48, 227 (1960).

5. G. B. Butler and J. J. Van Heiningen, J. Macro- mol. Sci.-Chem., A8, 1139 (1974).

6. G. B. Butler and M. A. Raymond, J. Polym. Sci., Part A, 3, 3413 (1965).

7. H. L. Panzik and J. E. Mulvaney, ibid., Polym. Chem. Ed., 10, 3469 (1972).

8. H. Kakiuchi, K. Fukuda, and M. Nakao, Abstracts, SPSJ 19th Annual Meeting, Tokyo, May 21, 1970, p 82.

9. K. Yokota, N. Hirayama, and Y. Takada, Polymer J., 7, 629 (1975).

10. G. B. Butler, J. Polym. Sci., Part C, No. 50, 163 (1975).

11. J. Roovers and G. Smets, Makromol. Chem., 60, 89 (1963).

12. G. Smets, P. Hous, and N. Deval, J. Polym. Sci., Part A, 2, 4829 (1964).

13. F. E. Bailey, Jr., J. P. Henry, R. D. Lundberg, and J. M. Whelan, ibid, Part B, 2, 447 (1964).

14. N. Murayama and Y. Amagi, ibid., Part B, 4, 119 (1966).

15. T. Otsu, S. Aoki, and R. Nakatani, Makromol. Chem., 134, 331 (1970).

16. T. Tanaka and O. Vog1, J. Macromol. Sci.Chem., A8, 1059 (1974).

17. T. Tanaka and O. Vogl, Polymer J., 6, 1552 (1974). 